\title{
EM BUSCA DAS APRENDIZAGENS NO CONCELHO DO ALANDROAL: A DIMENSÃO INSTITUCIONAL NA FREGUESIA DE NOSSA SENHORA DO LORETO/JUROMENHA
}

Bravo Nico (Centro de Investigação em Educação e Psicologia da Universidade de Évora/CIEP); Lurdes Pratas Nico (Direcção Regional de Educação do Alentejo); Luísa Serrano Carvalho (Instituto Politécnico de Portalegre); Patrícia Maurício, Patrícia Ramalho, Dora Pacheco, Sandra Ramos (Suão-Associação para o Desenvolvimento Comunitário); Florbela Valadas (Câmara Municipal do Alandroal); Joana Silva (CIEP)

\section{INTRODUÇÃO}

No âmbito da linha de investigação Educação e Território, promovida pelo Centro de Investigação em Educação e Psicologia da Universidade de Évora, iniciou-se, em Novembro de 2007, um projecto de grande magnitude: a cartografia da totalidade das aprendizagens disponibilizadas e concretizadas num determinado território (concelho do Alandroal/distrito de Évora), num determinado período (1997-2007).

Numa parceria alargada - que reúne, na actualidade, a Universidade de Évora, a Direcção Regional de Educação do Alentejo, a Delegação Regional do Alentejo do Instituto do Emprego e Formação Profissional, a Câmara Municipal do Alandroal, as seis Juntas de Freguesia do concelho (Nossa Senhora da Conceição, Santiago Maior, Capelins, São Pedro/Terena, São Brás dos Matos/Mina do Bugalho e Nossa Senhora do Loreto/Juromenha), a Associação de Desenvolvimento Comunitário SUÃO e o jornal regional Diário do SUL -, o projecto avançou para o terreno, em Março de 2008.

A primeira fase de concretização da pesquisa consistia em identificar, contactar e caracterizar todas as instituições presentes no território em estudo e, junto destas, recolher a informação necessária para a construção de uma completa cartografia das aprendizagens por elas disponibilizadas aos seus membros e aos habitantes do concelho.

Cerca de um ano após o início das actividades, no terreno da investigação, estão disponíveis os primeiros resultados, que dizem respeito à dimensão institucional de uma das freguesias e ao respectivo mapa das aprendizagens. 


\section{O TERRITÓRIO, COMO CONTEXTO EDUCACIONAL}

Como nos refere Patrício (2005:67), “somos quem somos e é a partir da nossa identidade que nos relacionamos...". Este ponto de partida é válido, em nossa opinião, para múltiplas dimensões da constelação relacional de cada indivíduo, família, instituição ou comunidade. De facto, a identidade é, em todas as situações, um poderoso instrumento de mediação determinando representações, opiniões, comportamentos e decisões, individuais ou colectivas.

Na dimensão educacional - aquela que nos leva a ser aquilo que queremos ser, partindo do que somos -, a identidade assume, de forma reforçada, o papel de mediação atrás referido. Na realidade, como continua a referir Patrício (2008:15), “o ser humano é inseparável da sua circunstância ou situação...". Esta circunstância, de contornos geográficos, demográficos, urbanos/rurais, sociais, económicos e culturais, determinará, certamente, uma determinada geometria, pessoal e local, na construção dos projectos educativos de cada indivíduo ou de cada contexto territorial local. Este pressuposto parece ser incontornável, até porque:

Não há globalização que altere esta realidade, a não ser que a globalização seja um projecto de aniquilação das diferenças humanas. Mas se somos tão ciosos da biodiversidade, que é a biodiversidade biológica, pergunto se não são mais fortes as razões para sermos ciosos da antropodiversidade, que é a diversidade cultural. Ora a diversidade cultural passa pela diversidade educativa. (Patrício, 2008:15)

Paraskeva (2008:36) refere-se também ao papel da identidade nos processos educativos, quando nos indica que "qualquer tentativa em torno da construção «local» da educação e do currículo não pode deixar de contornar as dinâmicas subjacentes à problemática de uma complexa identidade cultural, até porque educação e currículo são, em essência, processos de identidade”.

Por outro lado, na definição da geometria educacional de cada indivíduo, família, instituição ou comunidade, aos vértices decorrentes das características mais relacionadas com os contextos locais, teremos que adicionar outros vértices que resultam mais das circunstâncias políticas de escala macro-estrutural, que, "pelo peso do poder que auferem, moldam hoje as missões assinaladas às instituições escolares $e$ de formação de todos os níveis", até porque "só é adequada a cada momento uma política educativa que se defina e consiga dialogar permanentemente entre o que se 
enuncia (a partir das posições políticas, filosóficas, ideológicas) e o que se faz na prática, no dia-a-dia” (Ambrósio, 2005:71).

É com base nos pressupostos atrás indicados que pensamos existir uma relação profundamente significativa entre as circunstâncias de cada território e a forma como aí se desenham e concretizam os projectos educativos dos indivíduos, das famílias, das instituições e das comunidades.

No caso do Alandroal, concelho do interior alentejano, estas preocupações conceptuais manifestam-se, de forma mais exuberante, porque:

\footnotetext{
Mais do que em qualquer outra circunstância territorial - onde as dimensões demográficas, económicas e culturais possibilitam outra latitude reflexiva e decisional -, no interior, qualquer exercício de reflexão em torno das redes de aprendizagem ao longo da vida, deverá assentar num pensamento global, integrado e coerente. Um pensamento que, promovendo as potencialidades existentes e diminuindo as dificuldades evidentes, assuma a rede de qualificação territorial como um fundamental instrumento político para aumentar a capacidade do território em atrair pessoas e empresas, incrementar a capacidade geradora de riqueza e, em consequência, potenciar as melhores condições para garantir uma verdadeira coesão social que garanta efectivas condições de igualdade de oportunidades na realização pessoal, familiar $e$ profissional de cada cidadão. (Nico, 2008:10)
}

\section{O TERRITÓRIO DO ALANDROAL}

O concelho do Alandroal, território objecto da investigação, compreende seis freguesias, nas quais reside uma população adulta (com 18 ou mais anos e recenseada, eleitoralmente) de 5582 indivíduos.

De acordo com a informação disponibilizada pelo último procedimento de recenseamento da população (INE, 2002), o concelho do Alandroal possuía uma taxa de analfabetismo de $21 \%$, número que o colocou na $22^{\mathrm{a}}$ posição, a nível nacional, e em $12^{\circ}$ lugar, a nível da região Alentejo.

Em termos de freguesias do concelho do Alandroal, os números são os seguintes: 
Quadro 1 - Taxas de Analfabetismo das freguesias do concelho do Alandroal

\begin{tabular}{|c|c|c|}
\hline Freguesia & População adulta & Taxa de Analfabetismo (\%) \\
\hline São Brás dos Matos/Mina do Bugalho & 353 & 25,5 \\
\hline Nossa Senhora do Loreto/Juromenha & 145 & 24,4 \\
\hline Santo António/Capelins & 585 & 23,0 \\
\hline São Pedro/Terena & 757 & 20,3 \\
\hline Santiago Maior & 2172 & 18,4 \\
\hline Nossa Senhora da Conceição/Alandroal & 1570 & \\
\hline
\end{tabular}

Esta realidade remete-nos para percursos de qualificação da população adulta construídos longe dos espaços escolares formais. Nestas circunstâncias, os contextos não-formais e informais de aprendizagem assumir-se-ão, eventualmente, como estruturantes na construção dos projectos educativos dos indivíduos e respectivas famílias e comunidades.

Nesse universo dos contextos não-formais de aprendizagem, ganharão particular importância as instituições das mais diversas naturezas e áreas de actividade. Este pressuposto parece ganhar maior consistência em territórios de cariz marcadamente rural, pela ausência de espaços formais de aprendizagem alternativos à Escola e pela presença significativa de um conjunto de instituições recreativas, desportivas e culturais características do forte espírito associativo das comunidades locais portuguesas.

Por outro lado, ainda na dimensão institucional, importará considerar o contributo que as instituições empregadoras darão aos percursos de qualificação dos seus colaboradores.

Nestas circunstâncias, entendemos que a trajectória da investigação empreendida teria que passar, obrigatoriamente, pelo recenseamento de todas as instituições em actividade no território correspondente ao concelho do Alandroal, independentemente da respectiva área de actividade. Para tal, assumimos, como instituição toda a pessoa colectiva, juridicamente existente e fiscalmente activa. Como aprendizagem institucional, foi considerada toda a oportunidade de aprendizagem (de qualquer âmbito de formalidade) construída e/ou disponibilizada pelas instituições inquiridas, no período em estudo (1997-2007).

Com este filtro e com a expectativa de que a realidade institucional é determinante para o conhecimento das verdadeiras coordenadas que determinam a real 
geometria do mapa educacional de um território, o projecto de investigação seguiu a seguinte sequência de procedimentos:

Recenseamento de todas as instituições existentes no concelho do Alandroal, a partir das bases de dados oficiais existentes (Autarquias Locais, Governo Civil do Distrito de Évora, Instituto Português da Juventude/Direcção Regional do Alentejo, Direcção Regional de Educação do Alentejo, Instituto do Emprego e Formação Profissional/Delegação Regional do Alentejo, Listas Telefónicas da Portugal Telecom);

Desenvolvimento (construção e validação) de um questionário susceptível de identificar e caracterizar as aprendizagens existentes nas instituições (QAI/Questionário das Aprendizagens Institucionais);

$>$ Aplicação piloto do QAI na freguesia de Nossa Senhora do Loreto/Juromenha;

Aperfeiçoamento do QAI, com base nos resultados da aplicação piloto;

Aplicação generalizada do QAI em todas as freguesias do concelho do Alandroal;

Análise estatística da informação recolhida, com recurso à aplicação informática SPSS.

No momento em que se escrevem estas frases, encontram-se disponíveis alguns resultados da aplicação piloto do QAI na freguesia de Nossa Senhora do Loreto/Juromenha que, em seguida, se disponibilizam.

\subsection{A REALIDADE INSTITUCIONAL DA FREGUESIA DE NOSSA SENHORA DO LORETO/JUROMENHA}

Nesta freguesia, identificou-se a seguinte realidade:

Tabela 2 - Instituições e Aprendizagens identificadas na freguesia de Nossa Senhora do Loreto/Juromenha (período 1997-2007)

\begin{tabular}{|c|c|c|c|}
\hline Freguesia & \multicolumn{2}{|c|}{$\mathbf{N}^{\mathbf{0}}$ de instituições } & \multirow{2}{*}{$\mathbf{N}^{\mathbf{0}}$ de aprendizagens } \\
\hline \multirow{3}{*}{$\begin{array}{c}\text { Nossa Senhora do } \\
\text { Loreto/Juromenha }\end{array}$} & Identificadas & Inquiridas & \\
\cline { 2 - 3 } & 13 & 12 & 47 \\
\hline
\end{tabular}


Da leitura, simples, mas interessante, que se pode realizar da Tabela 2, podemos verificar que, atendendo ao facto de a população adulta da freguesia ser de 145 indivíduos, se podem retirar as seguintes inferências:

i) Existe uma taxa elevada de instituições (13), para a dimensão demográfica da freguesia (145 adultos);

ii) No período considerado (1997-2007), o número de aprendizagens disponibilizadas pelas instituições locais pode considerar-se significativo (47), o que poderá indiciar forte actividade associativa e, no seio desta, uma eventual preocupação com a qualificação da população.

Como exemplo, apresentamos, na Figura seguinte, o conjunto de aprendizagens identificado em duas das instituições inquiridas (Junta de Freguesia de Nossa Senhora do Loreto e a empresa Jurofrutas-Pomares do Monte Branco):

Figura 1 - Aprendizagens identificadas (exemplo)

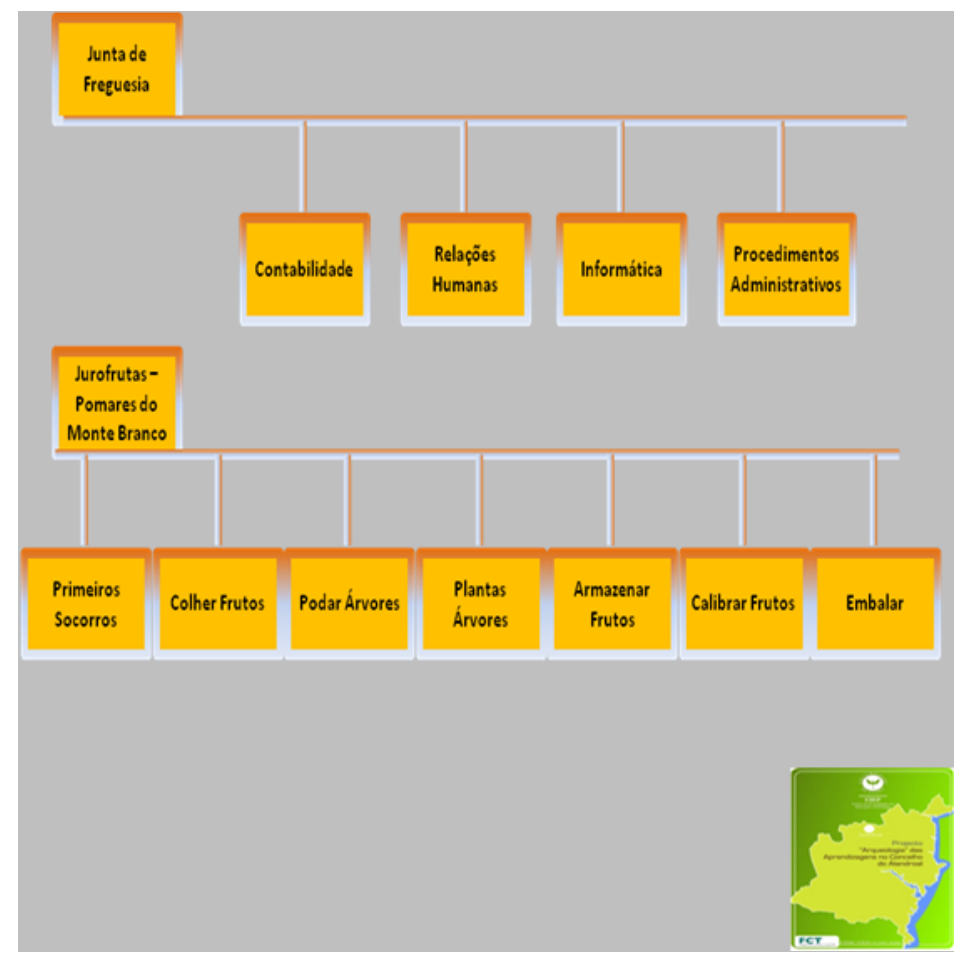


Como se pode observar, nos dois casos apresentados, foi possível identificar 4 aprendizagens disponibilizadas pela autarquia (todas elas relacionadas com a sua acção específica e dirigida aos seus responsáveis e colaboradores) e 7 aprendizagens concebidas e disponibilizadas por uma empresa (também desenhadas e orientadas para os seus funcionários).

Da análise que já foi possível realizar a cada uma das aprendizagens referenciadas, podemos indicar que apenas uma delas foi certificada (a aprendizagem da informática, disponibilizada pela Junta de Freguesia). No entanto, a certificação em causa não possui valor académico ou profissional legal.

\section{CONCLUSÃO}

No momento em que se apresentam estes resultados, poderemos concluir que, pelo exemplo que recolhemos em Nossa Senhora do Loreto/Juromenha, a rede institucional existente no território em estudo terá, eventualmente, um papel relevante no mapa educacional do território do concelho do Alandroal.

$\mathrm{Na}$ realidade, perece-nos ser interessante concluir a cartografia da rede de instituições e de aprendizagens e, em sequência, cruzar esse mapa com o mapa das aprendizagens concretizadas pelos indivíduos. Dessa forma, será possível avaliar, de forma objectiva e clara, a presença das instituições da sociedade civil na construção, individual, familiar e comunitária, no processo de construção dos diferentes projectos educativos. É essa a tarefa que executaremos até ao ano 2010.

\section{Referências Bibliográficas}

Ambrósio, T. (2005). "Futuros para a Educação: a inteligibilidade indispensável”. in Educação. Temas e Problemas. 1. pp: 69-78

Nico, B. (2008). "Aprender no interior português: Vértices para um pensamento integrado e uma acção responsável”. in Bravo Nico (Org). Aprendizagens do Interior: Reflexões e Fragmentos. Mangualde: Edições Pedago. pp: 9-19

Patrício. M. (2005). "Rumos desejados para a Educação portuguesa. Reflexão inicial, sob a influência de Teixeira de Pascoaes". in Educação. Temas e Problemas. 1. pp: 65-68 
Patrício, M. (2008). "Que rumo para a Educação no Alentejo". in Bravo Nico et al (Coords). Aprender no Alentejo - IV Encontro Regional de Educação. Évora: Universidade de Évora. pp: $11-17$ 